\title{
Entre a negrofilia e a negrofobia: caricaturas dos anos 1920 em perspectiva transnacional
}

\author{
Between Blackphilia and Negrophobia: \\ 1920s Cartoons in Transnational Perspective
}

Marissa Gorberg*

\section{Resumo}

Esse artigo examina caricaturas publicadas nos anos 1920 em revistas ilustradas de países integrantes de um circuito interatlântico de performances afro-diaspóricas. Contemplamos representações que versavam sobre personagens negros, protagonistas de expressões de música e dança de matriz africana que ganhavam popularidade junto a esferas elitistas, a fim de investigarmos processos que interferiram na construção de categorias sociais racializadas, sob perspectiva transnacional. À luz dos estudos pós-coloniais, inspirados por Frantz Fanon e Homi Bhabha, vislumbramos o exame de representações-estereótipos levando em conta ambiguidades subjacentes à sua elaboração. Produzidas na denominada Era do Jazz, as criações gráfico-humorísticas acionam reflexões acerca de trânsitos e trocas mediados por publicações periódicas que concorreram à elaboração de identidades, no balanço entre as estratégias racistas de poder e dominação e o sucesso e a afirmação da cultura negra amplificada em eixos diaspóricos de intercâmbio cultural.

Palavras-chave: Caricaturas; Anos 1920;

Racismo; Jazz; Revistas ilustradas.
Abstract

This article examines caricatures published in the 1920s in illustrated magazines of countries that belonged to an interatlantic circuit of Afro-diasporic performances. I contemplate representations of black characters, protagonists of African music and dance expressions that gained popularity in elite spheres, in order to investigate processes that interfered in the construction of racialized social categories from a transnational perspective. In the light of post-colonial studies, inspired by Frantz Fanon and Homi Bhabha, I envision the examination of the representations-stereotypes taking into account the ambiguities underlying their elaboration. Produced in the so-called Jazz Age, the graphic-humoristic creations provoke reflections on transits and exchanges mediated by periodical publications that contributed to the elaboration of identities, in the balance between racist strategies of power and domination, and the success and affirmation of black culture expanded in diasporic axes of cultural exchange.

Keywords: Caricatures; 1920s; Racism; Jazz; Illustrated Magazines.

\footnotetext{
* Fundação Getúlio Vargas (FGV), Rio de Janeiro, RJ, Brasil. marissagor@gmail.com <https://orcid. org/0000-0003-2382-6537>
} 


\section{INTRODUÇÃO}

Embora durante muito tempo tenha se cristalizado na historiografia a noção de que as vanguardas europeias e os intelectuais modernistas teriam "inaugurado" a valorização de temáticas e ritmos negros após a Primeira Guerra Mundial, é possível identificar o interesse por aqueles gêneros desde meados dos novecentos, em meio a seus trânsitos e transferências. Longe de ser um fenômeno nacionalmente restrito ou naturalmente determinado, gêneros musicais identificados com os escravizados e seus descendentes encontravam-se em fluxo para os Estados Unidos, a Europa e o Brasil no século XIX, como veículos de trocas e disputas de significados, inseridos em uma dinâmica transatlântica de intercâmbios culturais negros (Gilroy, 2001; Abreu, 2017).

Não obstante, nos anos 1920, expressões culturais de matriz africana, especialmente música e dança, ganharam popularidade inédita em capitais cosmopolitas do mundo ocidental. No circuito Paris, Londres, Nova Iorque, Berlim e Rio de Janeiro - que demonstrava aceitação para ritmos como maxixe, cakewalk e ragtime na virada do século XX (Putnam, 2013; Abreu, 2017) houve, na terceira década, uma invasão fonográfica incontestável das jazz-bands, reconhecidas internacionalmente como símbolo de modernidade. No período pós-conflito mundial, pós-pandemia de gripe espanhola, a sonoridade e os movimentos do charleston, shimmie, foxtrot e outras variantes adentraram esferas de elite - para alguns, como manifestação por excelência de raízes culturais populares (Hobsbawm, 2009); para outros, como sinal de degradação moral e ameaça às tradições.

A ascensão da cultura afro-diaspórica estava imbricada em uma rede transnacional de performances cuja potência afetou processos de construções identitárias e representações de identidades racializadas. A música se afirmou como um campo fundamental de conflitos, negociação e subversão dos papéis dos descendentes de africanos no mundo atlântico e nas lutas do pós-abolição, espaço aberto para a elaboração de novas hierarquias, em meio às discussões políticas e às questões raciais da época.

Nas últimas décadas, importantes estudos se voltaram ao exame de circuitos transatlânticos de cultura popular negra que influenciaram discursos e atitudes; autores que se debruçaram sobre espetáculos protagonizados por artistas afrodescendentes nos anos 1920 ressaltaram a importância que relações culturais além-fronteiras tiveram em processos de elaboração identitária racial e nacional (Vianna, 1995; Gomes, 2001; Bastos, 2005; Seigel, 2009; Shaw, 2018).

Interessa-nos investigar, sob perspectiva transnacional, o modo como a 
agência de atores culturais negros foi retratada nas caricaturas de revistas ilustradas do período, a fim de estabelecermos possíveis diálogos em suas experiências, para além de especificidades locais. As caricaturas apresentam vestígios que permitem entrever semelhantes práticas, impasses e reações vivenciados por artistas afrodescendentes em polos distintos, ampliando a compreensão da história da música negra no Brasil.

Os artistas do lápis, que buscavam inspiração no cotidiano, ofereciam suas versões para a celebridade inaudita da cultura afrodescendente nos anos 1920; o tema cruzava fronteiras e era estampado em publicações de países diversos que participavam de um fluxo internacional centenário de impressos, pessoas e ideias (Abreu; Deaecto, 2014). Os periódicos, integrantes de circuitos de difusão de informações e correntes de pensamento, ensejavam a circulação de imagens que, muitas vezes, apresentavam modos semelhantes de configuração.

As caricaturas do período - beneficiadas pelo desenvolvimento técnico que facilitava, por exemplo, a aplicação de cor - ofereciam um grafismo bastante moderno e inovador, caracterizadas por uma linguagem visual que as diferenciava da produção do século XIX. Ao invés de criações marcadas pelo realismo, plenas de esfuminhos e meios-tons, as produções dos anos 1920 apresentavam traços mais regulares e geométricos em elaborações mais limpas, inspiradas pelo Art-Déco (Teixeira, 2001).

Sua investigação se afigura uma lente singular para o exame das construções de raça na cultura visual naquele período, tributária da validação da escravidão e do racismo, mormente nos Estados Unidos e no Brasil, e da naturalização do colonialismo nas produções europeias (Rosenthal, 2016; Pieterse, 1992).

Em que medida as caricaturas dos anos 1920 apresentavam continuidades ou novidades em relação a uma longa e grotesca tradição racista de representações? De que modo abriam espaço para a projeção de artistas negros no mundo do entretenimento? Que aspectos oferecem para a percepção de conexões musicais e culturais do Atlântico negro?

Lembre-se que, naquele momento, nos debates que articulavam noções de raça e nação, a eugenia era uma preocupação constante, perceptível em propostas higienistas bastante aceitas, no início daquela década, em vários países (Schuster, 2014; Souza, 2016). Paralelamente à difusão dessas noções, verificou-se no período a incipiente propagação internacional de uma cultura jovem americana através de produtos culturais como revistas, livros, filmes e música. Com a adoção de novos padrões que atravessavam antigos dogmas baseados em clivagens de gênero e raça, uma nova moralidade acenava com 
possibilidades de interações sociais inauditas para a New Woman e o New Negro $^{1}$, figuras arquetípicas representativas do período convencionalmente denominado Jazz Age (Dumenil, 1995).

Em publicações que ocupavam papel relevante junto ao público leitor de Brasil, França, Inglaterra, Alemanha e Estados Unidos, nações integrantes de um circuito de performances afro-diaspóricas, eram divulgadas representações satíricas do "novo negro", que seria protagonista de novas formas de relações sociais, catapultado por sua inventividade artística. Com amplo destaque às caricaturas, tais publicações não correspondiam a espaços de autorrepresentação afrodescendente; do contrário, eram voltadas majoritariamente à vida mundana de camadas elitistas brancas, com pouco espaço para a inclusão da pluralidade social.

Inspiramo-nos nos estudos pós-coloniais de Franz Fanon e Homi Bhabha a fim de empreendermos um exercício de interpretação das elaborações gráficas, contempladas a um só tempo como fontes e objetos de análise. Através da interlocução multidisciplinar com a psicanálise e o pós-estruturalismo, Fanon atestou a negrofobia (Fanon, 1986), entendida como um sistema de atitudes discriminatórias socialmente operante. Homi Bhabha, por seu turno, aprofundou o entendimento acerca de modos de representação da alteridade e das estratégias utilizadas pelo discurso colonial (Bhabha, 1986).

Fanon e Bhabha chamam a atenção para fatores cruciais subjacentes à criação de estereótipos, que são a ambivalência identitária inconsciente e o fetichismo investido no objeto fóbico. A coexistência de impulsos e afetos contraditórios está no cerne da concepção do que (ou de quem) causaria inseguranças irracionais; daí porque os estereótipos encarnam um modo de representação complexo e contraditório, pleno de ansiedades, no interstício entre medo e atração, repulsa e desejo, fobia e fetiche (Bhabha, 1992, p. 191).

Tratadas como representações-estereótipos que operavam com a estética blackface, inscritas em um sistema social e cultural perpassado pelo racismo, as caricaturas escancaram, em uma primeira leitura, a estigmatização do ser negro limitado por esquemas corporais e comportamentais forjados majoritariamente por brancos, para leitores brancos.

Contudo, essa interpretação, conquanto seja pertinente, não é absoluta. Em diálogo com a obra de autores como Eric Lott (1993), Chad Heap (2009) e Marc Hertzman (2013), estudiosos do blackface e das imbricações entre música e raça, não desconsideramos o caráter de ambivalência na construção das representações estereotipadas.

À luz de recentes debates sobre raça e subjetividade, as caricaturas podem 
ser um ponto de partida para vislumbrarmos certas complexidades nas articulações de diferenças. Como produto cultural historicamente mediado, elas desvelam aspectos do imaginário e das sensibilidades do período, bem como o impacto que a existência de uma rede de trocas interatlânticas de cultura e música negra exerceu na elaboração de discursos a respeito de raça e nacionalidade.

\section{Le tumulte noir}

A cultura africana foi objeto de uma grande voga na Paris dos anos 1920, incensada por intelectuais franceses que percebiam naquelas expressões artísticas um antídoto para a civilização burguesa. Desencantada com a racionalidade, o cientificismo e o materialismo europeu, a vanguarda parisiense abraçou a cultura de origem africana como uma forma de contracultura. Em busca de "primitivismo", grupos de artistas europeus celebravam manifestações que consideravam "selvagens", "tribais" e "exóticas", como sinal inequívoco de sua própria modernidade. Negrofilia, nesse contexto, designava a tendência de glorificar a cultura afrodescendente, uma "moda" que reverberou para além da capital francesa (Archer-Straw, 2000).

Enquanto artistas europeus vislumbravam, naquilo que percebiam como primitivo, novas fontes de inspiração, muitos afrodescendentes, por sua vez, afluíram para a capital francesa em busca de uma propalada tolerância racial; a validação que logravam no universo artístico era percebida como via de acesso para o reconhecimento internacional e para a participação no cosmopolitismo.

Impulsionada pela guerra, a mobilidade de afrodescendentes abriu inúmeras possibilidades de encontros; ex-soldados, músicos, dançarinos, pintores e escritores se estabeleceram em Paris como um ambiente propício para seu êxito profissional. A cidade era uma espécie de contraponto ao bairro do Harlem, em Nova York, onde florescia o movimento Harlem Renaissance (inicialmente denominado The New Negro), que mobilizava artistas e intelectuais afrodescendentes no enfrentamento do racismo e na busca de uma redefinição de parâmetros identitários para si (Sweeney; Marsh, 2013).

A comunidade afrodescendente que se estabeleceu na metrópole parisiense assumiu um importante papel na vida intelectual, literária e política da cidade que ficou conhecida como Black Paris (Stovall, 1996). Integrados à cena cultural, seus integrantes tiveram participação ativa nos ritmos que embalavam a vida cotidiana; o jazz, elemento central da cultura afro-americana, se alastrou na cidade que era conhecida como o epíteto da cultura ocidental, e suas vibrações moldaram gostos e gestos, com ingerência nas representações de seus protagonistas. 
Figuras 1 e 2: La Vie Parisienne (1921).
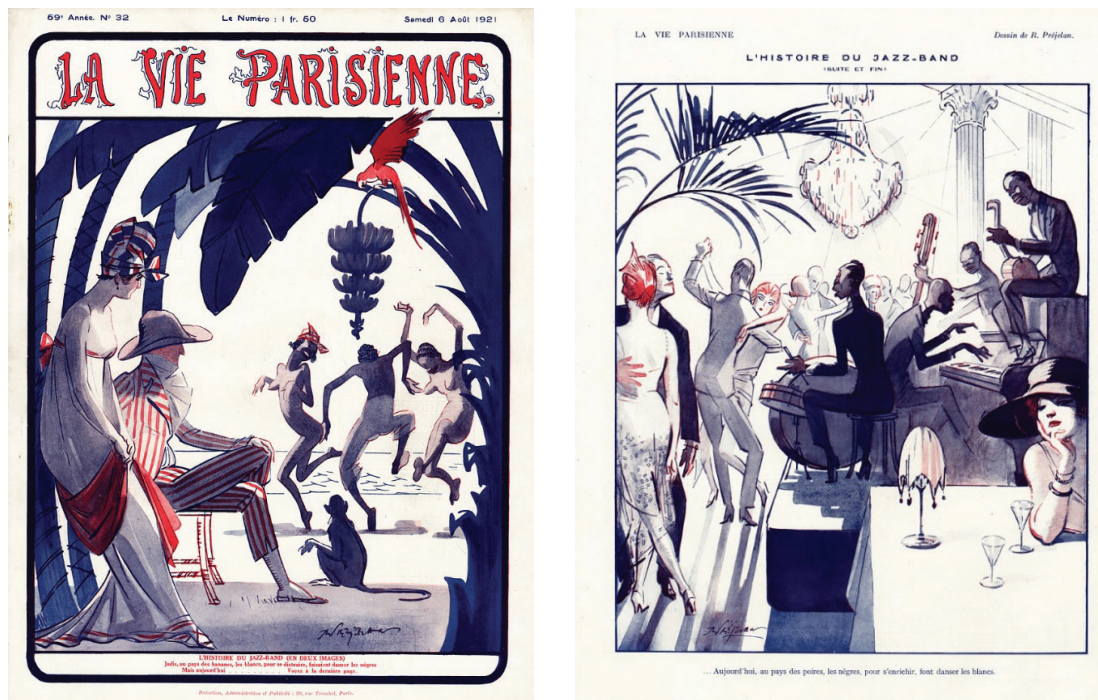

A História da Jazz Band em duas imagens: Antigamente, no "país das bananas", os brancos, para se distrair, faziam os negros dançarem. Mas hoje... [veja-se a última capa] Hoje, no "país das peras", os negros, para enriquecer, fazem os brancos dançarem.

Na capa e contracapa da revista francesa La Vie Parisienne, a composição díptica de René Préjelan atestava uma mudança nas relações raciais corporificada em temporalidades e espacialidades distintas. A julgar pelo diálogo que desvela o ponto de vista do casal europeu, haveria uma inversão de papéis típicos do colonialismo; se "antes" a invasão e a exploração eram perpetradas pelos "brancos", "depois" foram os "negros" que adentraram seu território e enriqueceram às suas custas.

Há um contraste explicitado entre o ambiente externo, tropical, o "país das bananas" - salientado por flora e fauna, bananeira e arara - e o ambiente interno do "país das peras", um salão adornado por colunas coríntias e lustre de cristal, sublinhando a identificação da cultura africana ao que seria o outro "selvagem" e a sua transposição ao mundo "civilizado", tributário da matriz greco-romana. A indumentária dos personagens também reforça essas associações, pois, se em um primeiro momento o casal europeu assiste, vestido, aos dançarinos seminus; na segunda composição os músicos afrodescendentes usam smokings, inscritos nos códigos vestimentares das metrópoles ocidentais.

É evidente a ironia que perpassa as caricaturas, que seriam capazes de 
provocar o riso no leitor provavelmente pelo caráter de absurdo que revestiria aquela alteração nos polos de dominação. As representações em questão demonstravam reconhecimento do sucesso que as jazz-bands usufruíam na urbe, ao passo que reforçavam imagens negativas que percebiam nas culturas africanas o atraso e a inferioridade.

No mesmo periódico, outra representação, dessa vez de Henry Fournier, igualmente atestava a ruidosa presença de performers negros nos palcos parisienses, apontados como "os mais novos representantes da velha alegria fran-

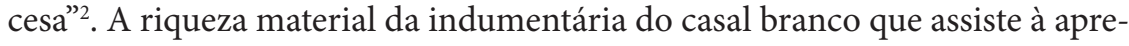
sentação - com joias, charuto e roupas elegantes - sugere um ambiente de elite. Enquanto os músicos são elaborados com feições que ressaltam olhos e boca de modo uniformizado, o artista que dança de costas para o público é retratado em pose animalesca e sexualizada, semidesnudo, em uma configuração erótica que sublinhava uma preconceituosa noção de propensão dos negros à licenciosidade. Não há uma definição explícita de gênero; os sapatos de salto, o cabelo curto e o corpo definido e torneado poderiam ser de um homem ou de uma mulher.

Figura 3: La Vie Parisienne (1927).

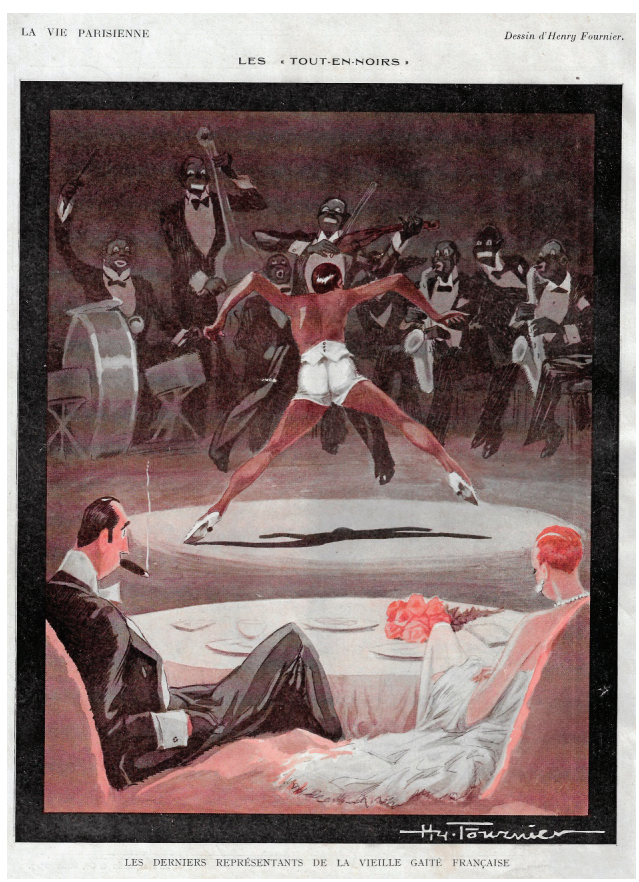


A ironia do título seria proveniente de uma inadequação da ocupação da cena cultural francesa por atores negros; o ar blasé da mulher à direita e o olhar de perplexidade do homem à esquerda contrastam com a energia inebriante dos artistas, e demonstram uma falta de sintonia nas vibrações dos espectadores brancos e dos protagonistas negros, senhores do espetáculo.

As conexões entre práticas diaspóricas transatlânticas são tangenciadas no editorial Enter The New Negro, publicado na revista Vogue inglesa em fevereiro de 1923. Ilustrado pelo cartunista mexicano Miguel Covarrubias, que mantinha relações estreitas com integrantes do Harlem Renaissance, o texto afirmava que

Nova Iorque está louca pelos negros. Paris está mais louca ainda, e logo Londres será a mais louca de todas. [...]

No século XVIII, nós ganhávamos dinheiro com os negros. No século XX, eles ganham dinheiro conosco. Nós costumávamos enviar a eles missionários. Hoje, mandamos a eles telegramas. [...]

O negro finalmente está sendo reconhecido. O crítico de arte mais distinto afirma que suas esculturas são melhores que as de Pheidias; os músicos afirmam que ele compõe melhor que Beethoven; os entusiastas da dança afirmam que ele

Figura 4: Vogue (1925).

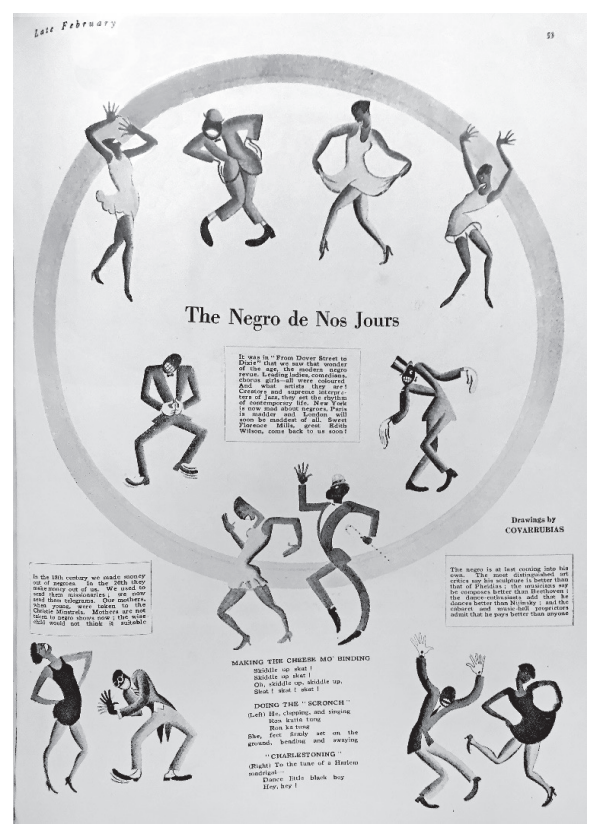


dança melhor do que Nijinsky. E os proprietários dos cabarés e cine-teatros afirmam que ele fatura mais do que todos os outros (Vogue, 1925. Tradução nossa).

Assim como nas representações francesas, o texto enunciava uma via inversa na exploração entre afrodescendentes e brancos, catapultada pela força de seu talento. Por um lado, podemos pensar na atuação positiva que a revista poderia exercer sobre o público ao ressignificar o posicionamento da cultura afrodescendente; por outro, não podemos deixar de questionar os limites que uma publicação dirigida a um público majoritariamente branco exerceria sobre a forma de assimilar essa mudança de locus social e econômico (Kalich, 2018).

Os personagens eram decalcados de forma cômica, em movimentos estilizados de danças executadas ao som das jazz-bands, com vestuário análogo ao que usavam músicos e dançarinas nos salões - para eles, fraque ou paletó e gravata; para elas, vestidos decotados e leves -, no caso, tão curtos que sublinhavam uma exibição corporal de modo fetichizado. Os desenhos acentuam o riso escancarado, os olhos e a boca saltados e as luvas brancas, característicos da prática do blackface.

Aquela forma de representação, com feições demarcadas de modo exagerado, seguia um padrão de figuração comum nas representações cômicas do século XIX, sintonizada com a imagem popular dos minstrels (menestréis) norte-americanos. Nos palcos, eles encarnavam uma percepção distorcida dos afrodescendentes pelos brancos, com olhos esbugalhados e lábios exageradamente grossos acentuados por maquiagem, ressaltando diferenças étnicas e culturais.

Em verdade, a prática do blackface remonta à Inglaterra shakespeareana do século XVII, quando os atores brancos pretendiam parecer "autênticos" (Thompson, 2021). A forma visual como os afrodescendentes foram representados na cultura popular era decorrente da institucionalização de imagens pejorativas e de um racismo estrutural que não estranhava brancos "se fantasiarem” de negros. Ao retratá-los com demarcações caricatas de suas feições, seu gestual e seu linguajar, o blackface exerceu papel significativo na perpetuação de imagens e atitudes racistas de modo global.

Mesmo sob variantes estilísticas, a caracterização estigmatizada era reproduzida por cartunistas de diversas procedências; o espanhol Eduardo Garcia Benito, responsável por inúmeras capas originais das revistas norte-americanas Vanity Fair e Vogue nos anos 1920-1930, ofereceu sua versão para a figuração de jazzistas negros. 
Figura 5: Vanity Fair (1926).

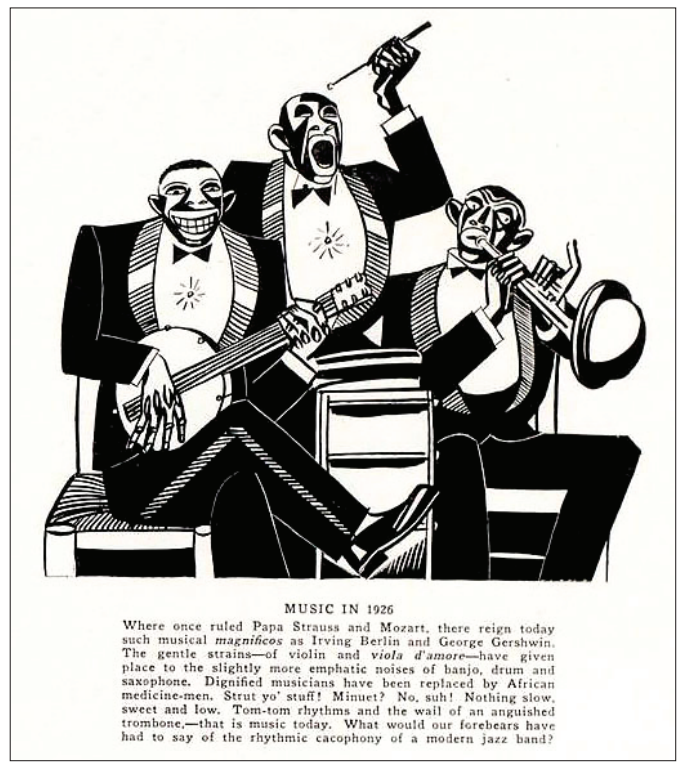

A ilustração fazia parte de um editorial que comparava transformações de três aspectos da vida norte-americana em tempos distintos, salientando contrastes entre tradicionalismo e modernidade "antes e depois", no amor, na dança e na música. Em relação a essa última, o texto destacava que "músicos dignos têm sido substituídos por curandeiros africanos”. Benito, especialista na estética Art Déco, compôs uma figuração tão preconceituosa quanto a verve do artigo; é flagrante o aspecto simiesco dos músicos, numa ode à diferença inferiorizante.

\section{O negrismo é a grande moda do momento}

Entre nós, o tumulte noir reverberou, nos anos 1920, de maneira própria, em meio a uma série de vetores culturais em fluxo e conexões de performances afro-diaspóricas estabelecidas. A fantasia de identificação com a cultura europeia, cujo ápice ocorrera no período convencionado como belle époque (18981914), permanecia como parâmetro valorizado pelas elites, mas começava a ceder espaço a outra fonte de influência: o modelo norte-americano, que ganhou corpo no período entreguerras, complexificando parâmetros identitários na própria matriz franco-inglesa.

No Brasil, de certa forma como "cópia da cópia", os marcos culturais esta- 
dunidenses foram apropriados sob diversas formas, sem escapar ao consequente questionamento. Assim como na Europa houve movimentos críticos a essa influência; a americanização não ficou imune à crítica intelectual nacional, que julgava, nos costumes difundidos por aquele país, uma decadência moral e uma degradação social.

O "americanismo emancipador", enunciado com ironia por Benjamim Costallat (1936, p. 161), provocava enfrentamentos nas relações de gênero que rompiam com dogmas patriarcais consolidados e nas relações racializadas mediadas pela música de matriz afrodescendente. A propagação do jazz era parte integrante do conjunto de elementos culturais que encontravam receptividade em alguns, repulsa em outros.

[...] a influência do povo americano tem crescido tanto e tão vertiginosamente nos últimos tempos, que já o Eco de Paris, em artigo especial, concita os franceses a libertarem-se do jugo americano [...]. A mania do jazz, do flirt, dos cabelos cortados e dos modos desenvoltos, diz ele, transformou a geração atual numa onda incivilizada (Ilustração Brasileira, 1926).

Percebe-se como a disseminação do jazz, sob a onda de negrofilia, em Paris, estava atrelada a outra onda: a do "americanismo" incipiente, que atingia antigos modelos identitários e comportamentais, lá e cá (Perreault, 2013). Além das alterações nas conformações de gênero, a presença da música de origem africana era também considerada uma "incivilidade". O jazz e a possibilidade de mobilidade social dos negros estavam inscritos no rol de inovações incômodas que seriam próprias de tempos modernos:

[...] Com o correr dos anos o negro foi mostrando aos poucos, quanto vale. Já não usa a velharia do "sus christo", não. Agora o que domina é o bon jour e o au revoir. Veio a época do jazz band. Em sua companhia vieram também, o almofadinha e a melindrosa de cabelo curtinho, à inglesa (D. Quixote, p. 13, 1924).

O trecho publicado na $D$. Quixote fazia parte de um conto eminentemente irônico assinado por "Lulu das ruas", que criticava tanto o comportamento de afrodescendentes que escapavam ao modelo escravocrata quanto o das elites que temiam a sua ascensão social.

Entre a aprovação que encontravam junto ao público e a rejeição que enfrentavam por parte de camadas preconceituosas, certo é que as jazz-bands se tornaram mesmo uma "mania" que se espalhou na então capital nacional, o Rio de Janeiro. À medida que se proliferavam, passaram a figurar como cha- 
marizes dos cine-teatros, dos cabarés, dos salões dos clubes; estabelecimentos como o Colyseu Moderno, o Cinema Theatro Central, o Casino Theatro Phenix e o Assyrio, entre outros, destacavam, em seus anúncios veiculados na mídia impressa, a presença daquele tipo de formação musical, a fim de atraírem sua audiência.

Dentre os inúmeros grupos que dominaram a cena cultural carioca na década de 1920, vários eram integrados por músicos negros, tais como os Oito Cotubas, integrado por Sebastião Cyrino, a Brazilian Jazz, do baterista J. Tomás (Cabral, 1993, p. 35) e os Oito Batutas, que protagonizaram uma experiência emblemática para a articulação das noções de raça, identidade e nacionalidade - o grupo estava inscrito de forma explícita na chamada "modernidade negra", membro eminente de uma rota interatlântica de conexões afro-diaspóricas.

Muito já se sabe sobre a trajetória dos Oito Batutas, mas vale à pena trazer à tona alguns aspectos. O grupo foi arregimentado em 1919 por Isaac Frankel, descendente de imigrantes judeus que possuía tino para o mercado de entretenimento ${ }^{3}$. Gerente do Cine Palais, Frankel convidou o grupo, que contava com talentos do quilate de Pixinguinha e Donga, para tocar na antessala do cinema, um reduto elitista da capital. Longe de passar ilesa a reações negativas, ainda sob influência do "racismo científico" predominante na virada do século passado, a iniciativa de destacar o talento afrodescendente em circuitos mais amplos estava imersa em debates sobre a pertinência ou não de sua inclusão.

Em 1922, custeados pelo mecenas Arnaldo Guinle e incentivados pelo diplomata Lauro Muller, os Oito Batutas rumaram à Paris para uma temporada de apresentações, convidados pelo empresário conhecido como Duque, lá estabelecido. A jornada foi "objeto de uma violenta discussão nos jornais" (A Maçã, 1922, p. 9). Recrudesceram reações explicitamente racistas, que condenavam a exposição, na cidade-luz, de um grupo brasileiro formado por negros; sem que faltassem opiniões contrárias, como a de Benjamim Costallat, que defendeu o grupo tal qual havia feito na ocasião de suas apresentações no Cine Palais (A Gazeta de Notícias, 1922).

Em Paris, foram anunciados como unique, revestidos de um espírito nouveau, marcados pelo viés percussivo do samba. Os Oito Batutas iam ao encontro do fascínio existente na França pela vivência do "exótico", que acolhia a significativa presença de negros em sua capital, de diversas nacionalidades (Bastos, 2005, p. 183). O grupo manteve estreito contato com o jazz americano, incorporando a seu repertório uma série de elementos inovadores, frutos de suas conexões com outros expoentes da música de matriz africana.

No regresso ao Brasil, os Oito Batutas participaram das comemorações do 
Centenário da Independência e deram prosseguimento a uma carreira exitosa; não à toa, registros historiográficos dos anos 1970 julgaram sua volta, após a temporada parisiense, um verdadeiro triunfo (Cabral, 1978). A temporada na cidade francesa denotava um status considerável; o grupo, "chancelado" pela saison parisiense, havia adquirido um capital simbólico de aprovação capaz de influenciar discursos e atitudes nacionais em relação à cultura afrodescendente.

As elites nacionais, plenas de preconceitos raciais, se viram diante da fama de formas de expressão artísticas de matrizes africanas no local considerado o núcleo mundial da civilização, da modernidade e do bom gosto. Se a ação daquela cultura não sepultou de vez antigas objeções, não se pode negar que influenciou a articulação de identidades racializadas.

$O$ vaivém da cultura popular afro-diaspórica ocorria em via de mão dupla; por exemplo: em 5 de agosto de 1922 estreava no Rio de Janeiro a prestigiosa companhia francesa Bataclan, que trazia entre suas atrações os artistas negros Douglas e Jones, sapateadores, e Gordon Stretton, líder de uma jazz-band (O Paiz, 1923). A convite da diretora, Mme. Rasimi, os Oito Batutas também ingressaram nos espetáculos da companhia, que causava celeuma pela inclusão da negritude em seu retrato de Brasil (Travassos; Lago, 2005; O Malho, 1922).

O provável sucesso das apresentações fez com que a jazz-band de Gordon Stretton permanecesse na cidade no ano seguinte; acompanhada de Douglas, Mary Cook e Jones, o grupo passou a apresentar um espetáculo solo, fartamente veiculado nos jornais, com muita repercussão (Correio da Manhã, 1923).

A presença ruidosa dos músicos negros nas jazz-bands que ocupavam palcos prestigiados do Rio de Janeiro é evidenciada em uma série de imagens gráficas do período. Tradicionalmente, as representações de afrodescendentes em caricaturas dos periódicos nacionais no período pós-abolição, editados majoritariamente por homens brancos, comumente os posicionavam como homens das ruas, malandros ou pedintes, associados à violência e à ignorância (Almeida; Silva, 2013). Por vezes, quando retratados em situações de ascensão social, eram depreciados, como se as clivagens de raça e etnia fossem determinantes de distinções de classe. Nessa perspectiva, é possível se considerar a inclusão de negros integrantes das jazz-bands como uma novidade manifestada nas representações à época. 
Figura 6: Costallat (1924).

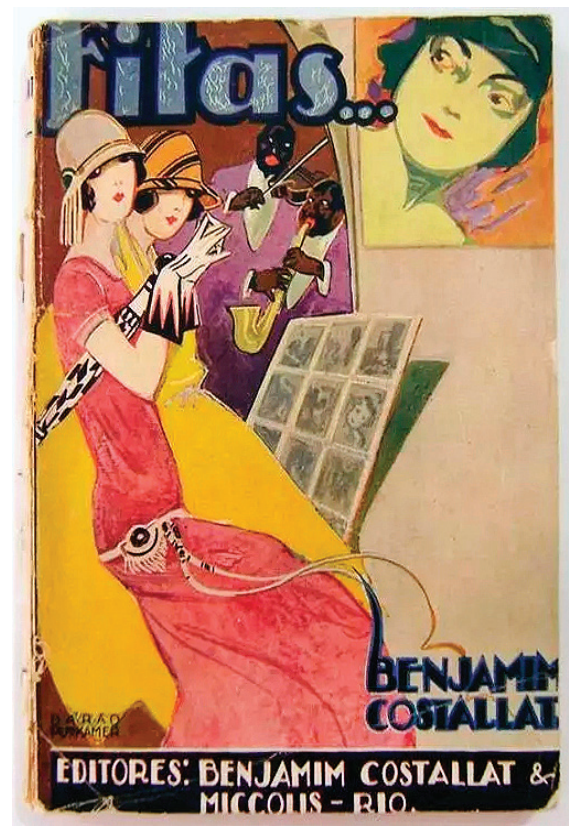

Na capa do livro Fitas..., uma coletânea de crônicas de Benjamim Costallat (1924), duas melindrosas arquetípicas - mulheres jovens, vestidas com vestidos tubulares e chapéu cloche, cabelos curtos, usando batom - aparecem defronte de uma tela e um cartaz de cinema. As "fitas" que nomeavam a obra eram uma alusão aos filmes em exibição nos cine-teatros, que consubstanciavam uma forma de sociabilidade alentada; antes da projeção, grupos musicais se apresentavam para entreter o público, tal qual os Oito Batutas faziam no Cine Palais, como mencionado. Os jazzmen afrodescendentes são retratados segundo a ótica blackface - olhos e boca saltados - e parecem mirar as moças que, por sua vez, têm o olhar direcionado para outro alvo que não os músicos.

Fitas... foi publicado pela Costallat \& Miccolis, uma editora pertencente ao próprio autor, de grande relevância no cenário cultural carioca dos anos 1920. Os títulos por ela lançados eram caracterizados por linguagem ágil e direta, temas polêmicos e investimento no projeto gráfico (França, 2011). Embora durante muito tempo a crítica literária tenha desprezado essas obras populares como um gênero "menor", algo revisto pela produção acadêmica recente, não há como negar que a editora de Costallat e suas publicações eram extremamente modernas. 
Os músicos afrodescendentes que marcavam presença na capa de Fitas..., sob esse prisma, aparecem inseridos em um panorama inovador que provocava fissuras em rígidas segregações calcadas em distinções de cor e classe. Note-se, contudo, que são posicionados ao fundo, em perspectiva menor, por detrás da cortina do palco, em uma representação que reforçaria um caráter coadjuvante.

Em outra configuração, na caricatura de Belmonte, a jazz-band estrelada por músicos afrodescendentes divide a cena com a corista e o compère (mestre de cerimônia), que pareciam embalados pelo som:

Figura 7: Frou-Frou (1924).

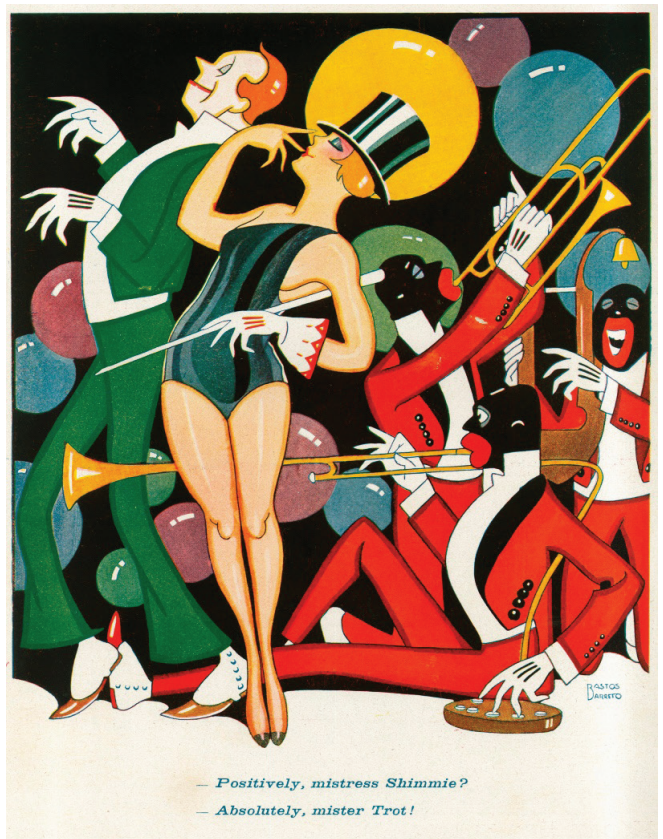

- Positively, mistress Shimmie?

- Absolutely, mister Trot!

Novamente a estética blackface se faz presente, nos rostos dos músicos que tocam instrumentos exóticos que integram sopro, percussão, cordas e até um sino em sua configuração; o jazz causava impressão não apenas pela formação do conjunto e pelos ritmos apresentados, mas também pela inclusão de efeitos instrumentais e sons caseiros (Labres Filho, 2014, p. 17). O shimmie e o foxtrot são ressaltados no trocadilho do diálogo anglófilo dos personagens, que afirmavam "positivamente" e "absolutamente" o som dos ritmos os quais causavam 
furor nas revistas teatrais onde vicejavam jazz-bands que acionavam discussões sobre raça e nacionalidade.

Não se pense, contudo, que o triunfo encontrado nos palcos estaria livre de manifestações do racismo endêmico que há séculos permeava o tecido social; os artistas afrodescendentes e o tipo de música que tocavam enfrentariam fortes preconceitos que reiteravam aspectos negativos a eles identificados, perceptíveis nas elaborações de caricaturas do período.

Figuras 8 e 9: Frou-Frou (1926).
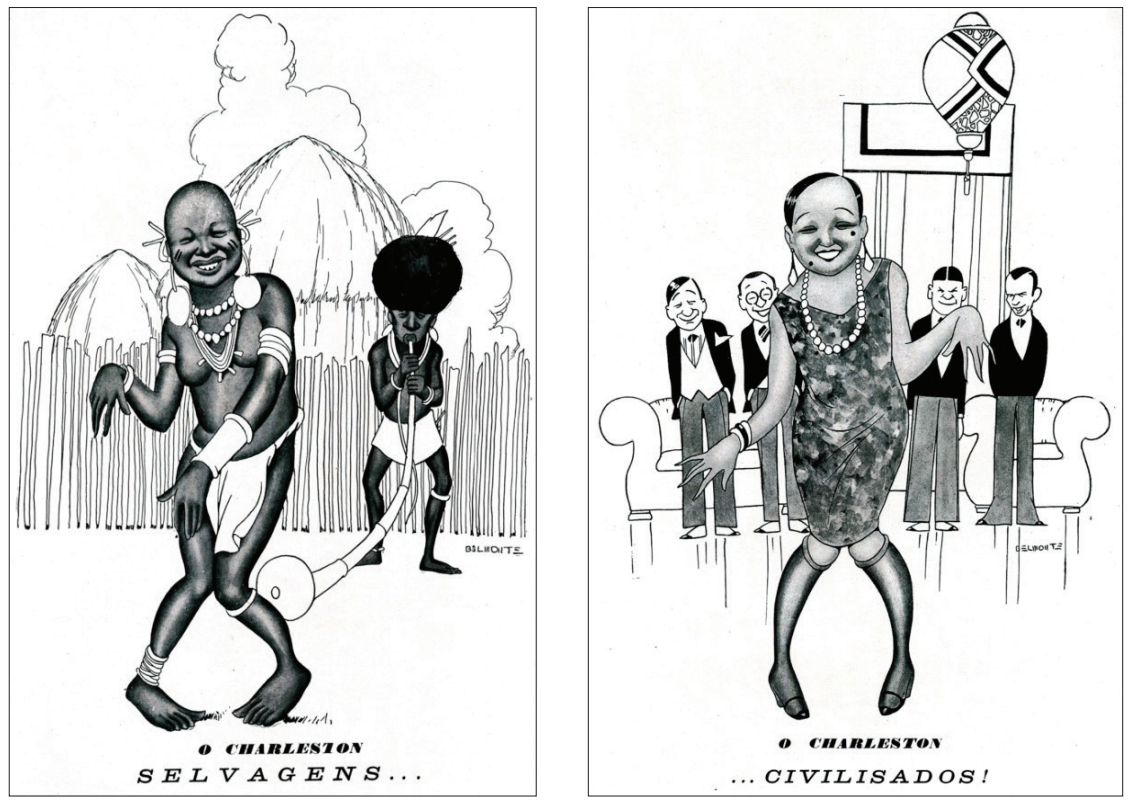

O Charleston

Selvagens...Civilizados!

O vínculo entre o ritmo do Charleston (uma variante do jazz) e a noção de selvageria primitiva é explicitado na representação de Belmonte. Como uma espécie de “jogo dos 7 erros”, o caricaturista opõe duas composições análogas, caracterizadas por várias similaridades: a cena do divertimento em dança e música; a disposição dos personagens, com mulheres em primeiro plano e homens no segundo; a posição corporal delas, com joelhos encostados, pés virados para dentro, braços em movimentos (típicos daquela dança), sorriso no rosto; o uso de acessórios como colares, brincos e pulseiras. As diferenças servem para realçar o recorte espacial distinto: a caricatura "Selvagens" é am- 
bientada em tribo africana, com habitação e indumentária correspondentes e atores negros, enquanto os "Civilizados" são brancos, estão em salão interno, com mobiliário art-déco e vestuário moderno - destaquem-se as meias finas enroladas nos joelhos da mulher, uma tendência bastante inovadora à época, e as amplas calças Oxford dos rapazes, também alinhados com a moda.

Belmonte questiona os parâmetros civilizatórios que abraçavam a música de origem africana, ridicularizando as mulheres que dançariam como selvagens; as representações promoviam o escárnio por sugerirem que a adesão àquele tipo de dança e ritmo seria sinal de selvageria, a um só tempo degradando a cultura de origem afrodescendente e as pretensões de camadas que adotavam comportamentos que se afastavam de antigos esquemas.

Figura 10: Life (1926).

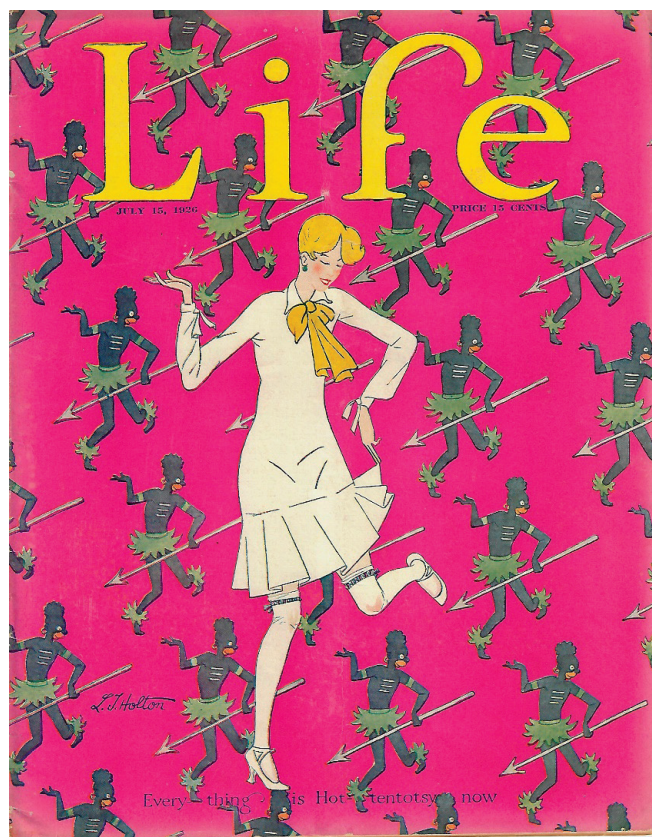

A equiparação de mulheres modernas a tipos negros retratados como selvagens pode ser observada também na revista Life, ilustrada por L. J. Holton no mesmo período, na qual os personagens dançam com gestual espelhado. A jovem personagem branca, que usa vestido tubular e cabelos curtos, com meias de seda presas por cintas-ligas acima do joelho ${ }^{4}$, denota ousadia a seu tempo. A fruição de música e dança de origem africana fazia parte do repertório de ino- 
vações adotadas por aqueles que não se submetiam a rigorosos moldes tradicionais e se permitiam novas experimentações, tanto na composição visual quanto na adesão a ritmos e gestos envoltos em maior liberdade, energia e pulsão rítmica. A representação não escapa à configuração preconceituosa que apontava expressões africanas como exóticas e primitivas, evidente na indumentária tribal arrematada com uma lança. É de se notar, também, que a mulher branca domina o centro da cena como figura principal, enquanto os tipos negros são retratados em tamanho menor, como "pano de fundo", uniformizados e despersonificados. O que não se pode negar, outrossim, é que a cultura de origem africana era "o" assunto primordial estampado na capa de uma célebre revista norte-americana, valorizada por integrantes de uma elite branca.

A persistência de combinações gráfico-satíricas de negros ligados a uma ideia desdenhosa de primitivismo emerge em capas da revista $O$ Malho ilustradas pelo renomado J. Carlos, voltadas ao fenômeno de popularidade das jazz-bands:

Figura 11: O Malho (1924).

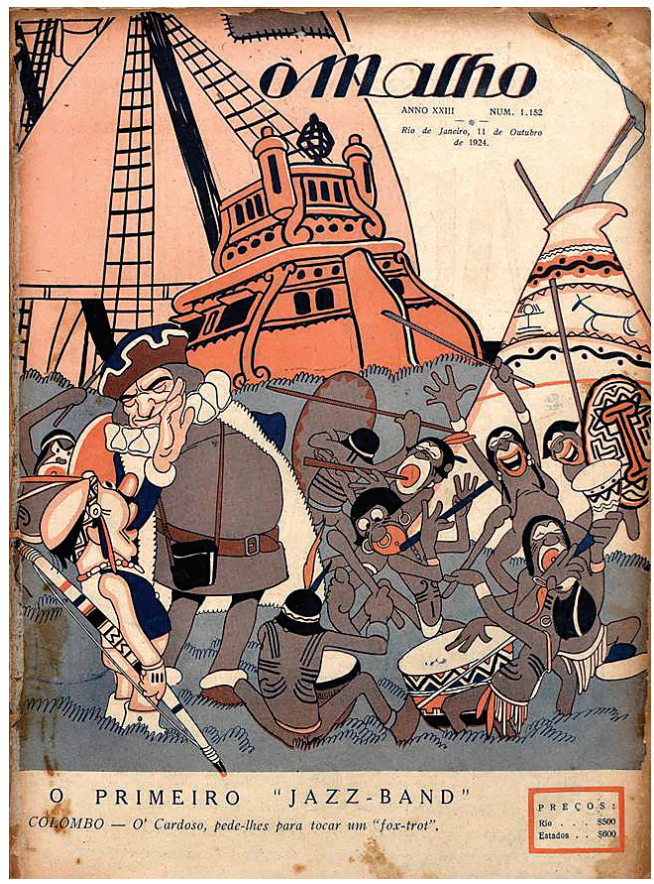

O Primeiro "Jazz-Band"

Colombo - Ó Cardoso, pede-lhes para tocar um "fox-trot". 
A escolha do tema para figurar na capa da popular revista O Malho corrobora a importância de sua presença no cenário cultural carioca do período. Contudo, a situação retratada reitera uma imagem racializada dos músicos afrodescendentes; assim como na revista francesa anteriormente mencionada, há uma correlação com esferas de poder do período colonial e com a dicotomia estabelecida frente ao "outro". Diante de sua majestosa nau, evocadora de Grandes Navegações e "Descobrimentos", o personagem Colombo - uma explícita referência ao navegador italiano Cristóvão Colombo - conversa com uma espécie de encarregado, o personagem Cardoso, que, assim como ele, é branco, mas aparece vestido com peças indígenas (colar, arco, diadema), sugerindo uma familiaridade com os nativos. A graça da situação adviria pela identifica-

Fig. 12: O Malho (1923).

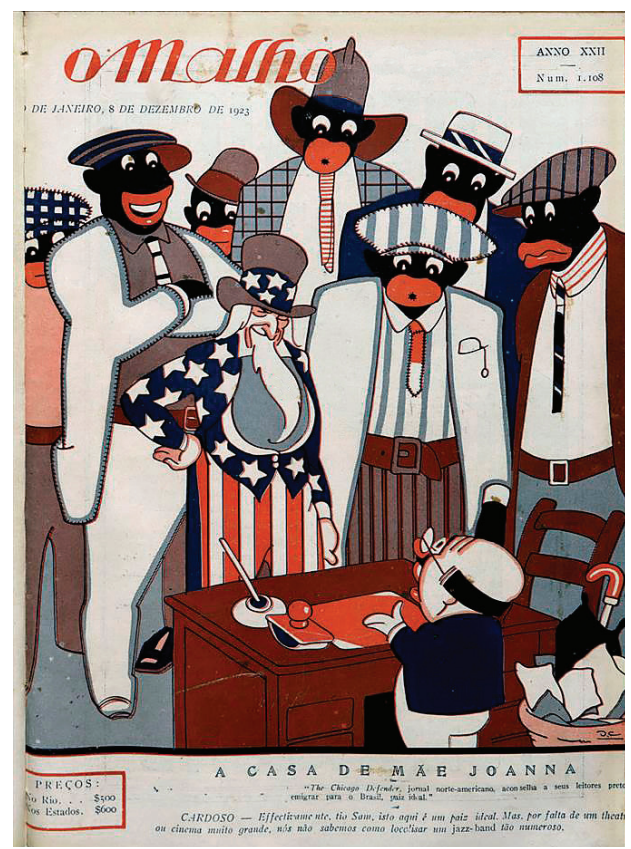

A Casa de Mãe Joana

"The Chicago Defender, jornal norte-americano, aconselha a seus leitores pretos a emigrar para o Brasil, país ideal".

CARDOSO - Efetivamente, tio Sam, isso aqui é um país ideal. Mas, por falta de um teatro ou cinema muito grande, nós não sabemos como localizar um jazz band tão numeroso. 
ção das jazz-bands modernas e dos seus integrantes com grupos tribais dos países colonizados. Defronte a uma tenda adornada com motivos rupestres, os músicos negros que tocam ruidosamente instrumentos de percussão e sopro adornados com ornamentos africanos são delineados de forma caricata, com olhos e bocas exageradas; parecem extremamente felizes naquele encontro intra mundi, como se não houvesse um pesado fardo de submissão pela violência, decorrente das formas de apropriação daqueles territórios e suas populações levadas a cabo pelos europeus. A adoção de traços alegres e risonhos, comuns em representações-estereótipos do séc. XIX (Abreu, 2017), reforçava a ideia de que os negros possuiriam uma natureza infantil e inferior, sendo, consequentemente, inaptos para o responsável exercício da cidadania.

As barreiras de intolerância enfrentadas por afrodescendentes são flagrantes em outra capa da mesma revista $O$ Malho, que também satirizava uma situação vexatória envolvendo jazz-bands:

A caricatura fazia menção a um programa de imigração afro-americana para o Brasil que chegou a ser cogitado por jornais dos Estados Unidos dirigidos àquele público; o Chicago Defender, maior periódico afro-americano da época, havia noticiado, na década anterior, que o "Brasil acolhe afro-americanos" e que o país seria um "campo elísio para a população negra". As notícias veiculadas naquele e em outros jornais sobre uma suposta receptividade brasileira para imigrantes afro-americanos, contudo, não seriam factíveis, pois face àquela possibilidade foram desencadeados movimentos contrários no Brasil, inclusive um projeto de lei apresentado ao Congresso com o objetivo específico de interditar a imigração de afrodescendentes. Tal projeto não foi aprovado oficialmente, mas o Ministério das Relações Exteriores orientou os Consulados à não emissão de vistos para afro-americanos, fossem imigrantes ou turistas (Andrews, 2017, pp. 23-26).

Sob o traço de J. Carlos, a criação gráfico-satírica da capa ironizava a pretensão afro-americana ao considerar que o Brasil seria "a casa da Mãe Joana” ao abrigar aqueles imigrantes - lembrando que a expressão remete a um lugar sem ordenação, onde imperaria o "vale tudo", a confusão e a balbúrdia. Novamente o autor inclui o personagem Cardoso, dessa vez no posto de funcionário da imigração; ele até confirma a versão do Brasil divulgada nos Estados Unidos - um "país ideal", pautado por democracia e tolerância - mas, na prática, proíbe a entrada dos afro-americanos sob a alegação de que não haveria teatro ou cinema suficientemente grandes para abrigarem-nos; como se um grupo de negros bem-vestidos só pudesse ser integrante de alguma jazz-band.

Ao longo da década de 1920, enquanto aquela formação musical se espraiava pelos palcos cariocas, muitas caricaturas incorporaram seu comparecimento, mas o fizeram sob um olhar impregnado de prejulgamentos esquematizados. 
Figura 13: Para Todos (1926).

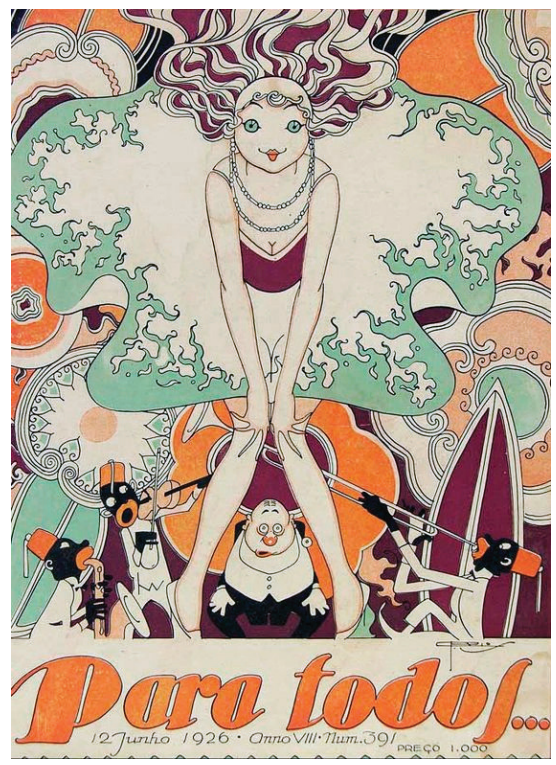

Figura 14: Para Todos (1927a).

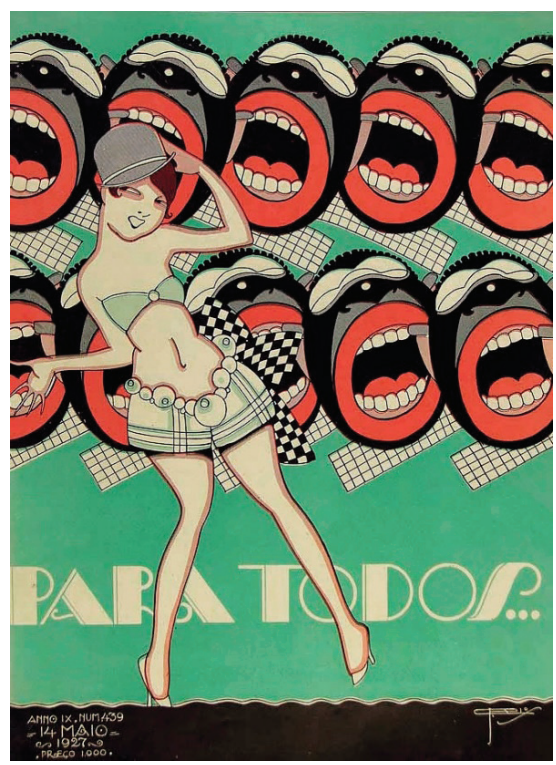

Figura 15: Para Todos (1927b).

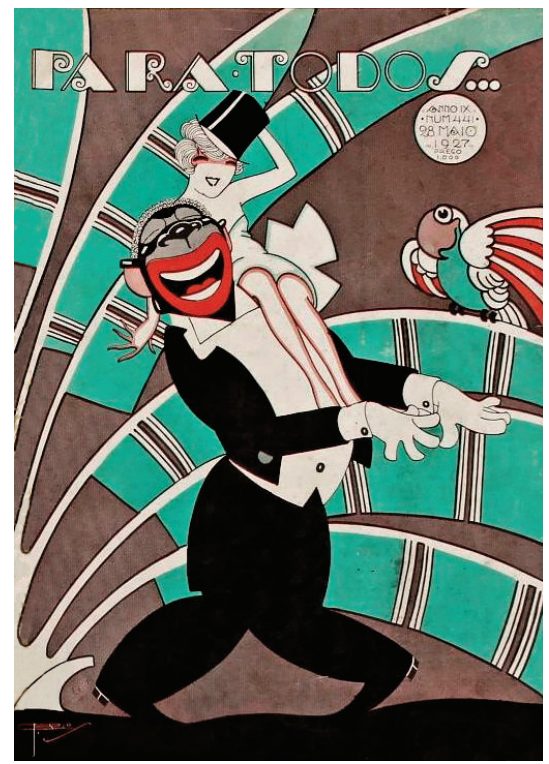


Nas capas da revista Para Todos, os artistas negros são retratados cantando, tocando e dançando, sempre em papel secundário, enquanto as mulheres brancas, atrizes e vedetes de teatro, ocupam o plano principal, à frente deles ou, no último exemplo, em cima deles. O modo de retratá-los renova uma ideia de inferioridade; ao acomodar a mulher sobre o ombro do homem que parece dançar charleston, o caricaturista evoca a submissão escravocrata e faz pensar nas cenas coloniais nas quais os africanos suportavam o fardo de carregar os brancos. Ademais, é traço comum a reiteração do estereótipo difamatório, com faces desumanizadas, bocas, dentes e olhos ampliados de forma grosseira, em reprodução do modelo prejudicial dos minstrel shows.

É de se notar que essas duas últimas caricaturas foram publicadas no período coincidente às apresentações da Companhia Negra de Revistas, entre julho de 1926 e julho de 1927. Formada integralmente por artistas afrodescendentes, a troupe, que era comparada à Revue Nègre parisiense, encantou público e crítica (Barros, 2005); seus espetáculos corporificavam uma grande novidade ao apresentar o negro em posições que fugiam aos papéis subalternos, ingênuos e infantilizados (Domingues, 2009).

Não é o que vemos nas caricaturas de J. Carlos, que mostravam esquetes estrelados por atrizes brancas, enquanto relegavam os artistas negros a um lugar secundário, retratados sob clichês que acentuavam diferenças. É possível que o caricaturista tenha buscado inspiração em outros espetáculos que não os da Companhia Negra de Revistas; ou tenha oferecido a sua versão reinterpretada para a cena teatral afrodescendente, que tanto angariava aplausos quanto violentos ataques racistas.

Fato é que não podemos ignorar que o artista expoente da caricatura brasileira, autor das capas d'O Malho e da Para Todos aqui abarcadas, compôs uma série de representações imbuídas de posicionamentos hostis. Recentemente, a historiografia tem reconhecido o lado menos louvável do talentoso J. Carlos, atestando a presença de "figuras negras brutalizadas, bestializadas, animalescas” em sua obra (Cardoso, 2019). Embora não se possa desconsiderar o peso do preconceito racial no contexto da época em que aquelas caricaturas foram produzidas - caso contrário, não seriam inteligíveis ou mesmo risíveis para o público a que se destinavam -, tampouco se deve minimizar a força daquelas figurações para a divulgação de estigmas. J. Carlos contribuiu para a contaminação do racismo por meio de suas criações, enquanto reagia a um fenômeno cultural inegável impulsionado pela mobilização afrodescendente.

Ele certamente não era o único a retratar negros de modo racista naquele momento. Em grande parte das revistas ilustradas, era comum se encontrarem 
representações que acentuavam distinções econômicas, culturais e sociais perpassadas pela noção de raça e suas implicações excludentes, i.e., os personagens negros figuravam nas caricaturas como pobres, pedintes, ignorantes, favelados, em situação de servidão subalterna a algum patrão branco. Para as mulheres negras, invariavelmente as representações recaíam sobre a função de empregada doméstica, com destaque a um modo de falar que, por não obedecer à norma culta (até porque não possuíam amplo acesso à educação formal), era extremamente pejorativo.

As novas configurações decorrentes da aclamação das jazz-bands em redes culturais transnacionais produziram efeitos nas construções identitárias e nas representações balizadas pelo conceito de raça; não sem provocarem reações adversas estaiadas em forte objeção à ampliação daquela presença. Se é verdade que as expressões artísticas afrodescendentes ganhavam espaço e reconhecimento por parte de grupos mais afeitos à diversidade e mais ávidos por parâmetros de modernidade, efetivamente as inovações determinadas por aquela agência esbarravam em modos arraigados de divisar o "diferente".

As representações decalcadas em caricaturas do período não fogem a essas ambiguidades; a figuração de afrodescendentes em novas posições (notadamente a de artista de sucesso), sob nova roupagem (com indumentária correspondente a padrões correntes de "elegância"), em ambientes geralmente frequentados até então apenas por cidadãos brancos (clubes, teatros, salões de festas do Centro do Rio de Janeiro) era evidente, reforçando uma ideia de aprovação e acolhimento de sua cultura e sua presença, haja vista a popularidade dos espetáculos em que atuavam. Assim como eram evidentes, também, as respostas a essas inovações, em grande parte preconceituosas diante da "ameaça" de proximidade com esferas que sempre estiveram sob controle, mantendo distância social e econômica.

O olhar transnacional contribui à observação do fluxo simbólico procedente de redes culturais afro-diaspóricas e das respostas sociais que se encontravam, no circuito interatlântico, enunciadas em representações caricaturais dedicadas àquele universo. Em outubro de 1926, a revista Vogue britânica atestava que "A Negritude é para o Século XX o que a Chinoiserie foi para o Século XVIII"; dois meses depois, a revista Careta afirmava que "o negrismo é a grande onda do momento" (Careta, 1926, p. 23). Ao divisarmos a produção publicada em periódicos de capitais metropolitanas ocidentais, percebemos que a ampliação da atuação afrodescendente se afigurava intrínseca ao próprio cosmopolitismo, mas condenada a centenários embates. 
Figura 16: Kladderadatsch (1923a).

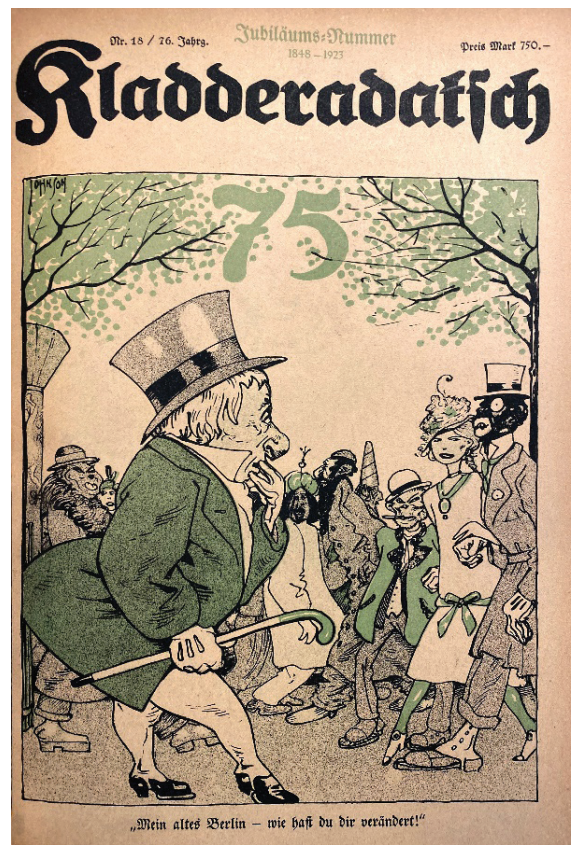

Minha velha Berlin - como você está mudada!

A capa da revista alemã Kladderadatsch ${ }^{6}$ escancara o racismo presente nas ruas de Berlin naquela década, corporificado no comentário do personagem aristocrático em primeiro plano, que se espanta ao perceber um casal interracial caminhar publicamente de mãos dadas. A cidade, também conquistada pelas jazz-bands nos anos 1920 (Wipplinger, 2017), provavelmente testemunhava novas possibilidades de encontros que não se restringiam a impedimentos delimitados por percepções raciais.

Em outra caricatura de Oskar Garvens na mesma revista, a estupefação do personagem "Americano" face à escolha de "Marianne" é uma construção metafórica que contrapõe os Estados Unidos, marcado por forte racismo, à França (através de Marianne, figura alegórica que representa a República Francesa), mais permeável à presença negra. Numa e noutra representação alemã há um destaque para a feiura e a feição animalesca imputada aos afrodescendentes, sem disfarces para o modo difamatório com que eram retratados.

A aproximação afetiva interracial tematizava inúmeras outras versões gráficas, sob diversos enfoques: 
Figura 17: Kladderadatsch (1923b).

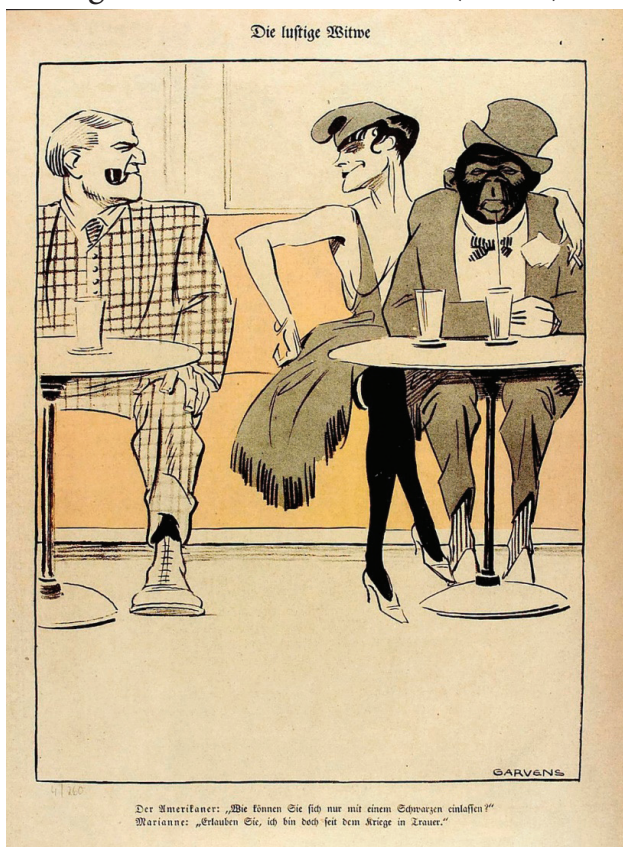

O Americano - Como você pode se envolver com um negro?

Marianne - Com licença, estou de luto desde a guerra.

Na capa da francesa La Vie Parisienne ilustrada por Georges Léonnec, a moça com roupa sensualizada, decotada e transparente, olha de forma arrebatada para dois homens negros que retribuem o contato visual com um sorriso, em poses simétricas. Eles usam a vestimenta comumente adotada por músicos de jazz-bands e sapateadores, incluindo gravatas borboletas - seriam as "papillons noirs" mencionadas no título metafórico? Um coração vermelho vivo ao fundo emoldura os personagens, comunicando sentidos de encantamento e paixão.

Nem todos os desdobramentos decorrentes de interações inéditas eram marcados por um pendor totalmente negativo. No Rio de Janeiro, a presença de atores afrodescendentes nos palcos acionava desejos e fantasias de encontros amorosos em perspectiva distinta do paradigma miscigenatório que predominara desde fins do século XIX, norteado pela "política do branqueamento". 
Figura 18: La Vie Parisienne (1925).

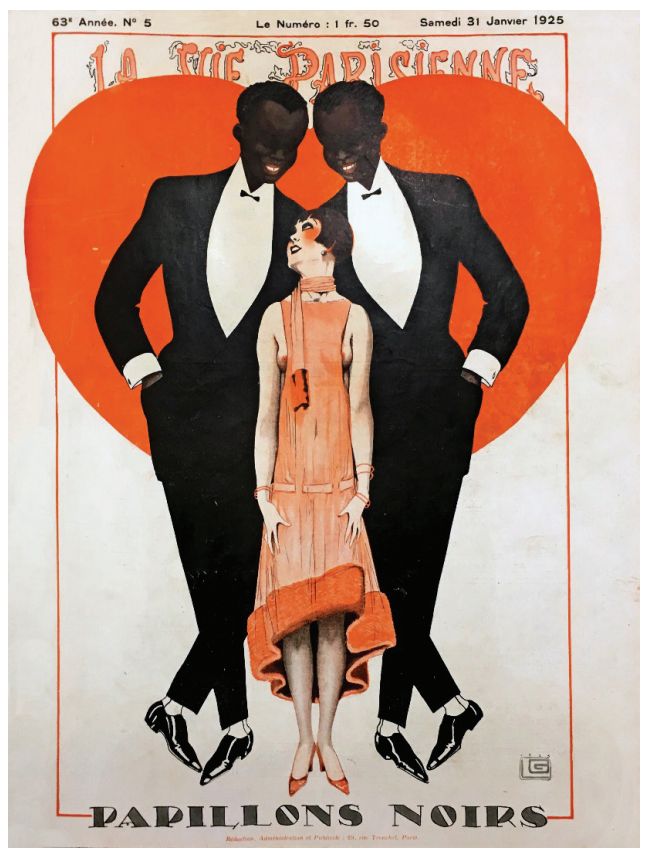

Em clara referência aos músicos negros que se apresentavam junto à Companhia Bataclan em 1923, frequentada por um público sofisticado, o "almofadinha bataclânico" da caricatura de Belmonte é retratado como um homem capaz de despertar a atenção da mulher branca, rica, que parece preferir um jovem galante ao invés do companheiro idoso e sisudo, independentemente de sua cor de pele. O preconceito permanece na concepção caricatural do homem negro, com características físicas "carregadas", de forma homogênea e extrapolada. Traços que não impediram a personagem de Belmonte de se voltar, com interesse, ao afrodescendente que cruzou seu caminho na rua; note-se que ele era um almofadinha com vestimenta sofisticada e pertencente a um universo artístico de sucesso (bataclânico), como se a moda, o capital e a fama fossem elementos atenuantes de racismo.

Produtos da cultura de massas - espetáculos teatrais e musicais, revistas ilustradas, caricaturas - franqueavam brechas à presença negra que, embora muito referenciada a estereótipos preconceituosos, se impunha tanto nas páginas de revistas como a superelitista Frou-Frou quanto nas ruas e nos salões da Zona Sul. 
Figura 19: Frou-Frou (1923).

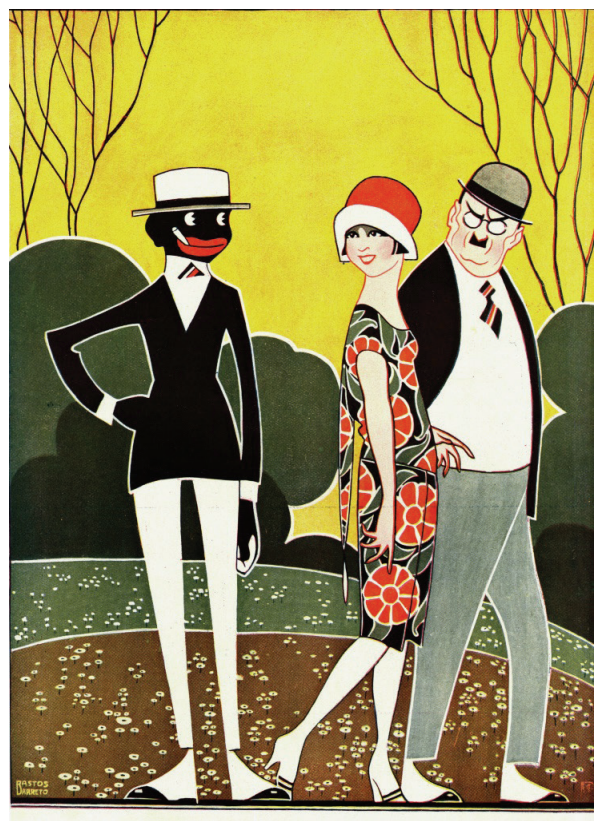

- Meu Deus! Que almofadinha tão "bataclânico!..."

\section{Conclusão}

A observação de caricaturas publicadas em periódicos dos anos 1920 que não primavam pela abertura de espaço à autorrepresentação negra permite entrevermos uma série de aspectos concernentes às negociações da imagem e do lugar social dos afrodescendentes, mediadas por suas expressões culturais.

O conjunto de imagens gráficas reforça noções apontadas pela historiografia em relação ao papel do jazz como verdadeiro símbolo de modernidade propagado em redes de conexões simbólicas; não há como se negar a importância de sua atuação no cenário de entretenimento de metrópoles que participavam de um circuito interatlântico de performances afro-diaspóricas, do qual o Rio de Janeiro fazia parte.

Outrossim, são evidenciadas as resistências que manifestações de cultura negra enfrentavam, sugeridas nos indícios de sentidos racistas semelhantes encontrados em representações-estereótipos do período. A intensificação de sua 
presença nos palcos era uma conquista, mas não era um consenso, provocando enfrentamentos por grupos afeitos a padrões preconceituosos estabelecidos.

Enquanto as caricaturas apresentavam inovações na forma gráfica e na temática voltada às jazz-bands, abrindo janelas para a divulgação e a valorização de gêneros musicais negros, perpetuavam velhos marcadores culturais hierarquizantes. A inserção da cultura afrodescendente nas páginas das revistas ilustradas não fez cessar uma tradição racista entranhada no tecido social em função da percepção do "outro" calcada na distinção de etnias; uma percepção equivocada que ainda nutre profundas desigualdades.

É importante destacar-se que, independentemente da ascendência dos caricaturistas, era traço comum a associação a noções de selvageria, licenciosidade, infantilidade e inferioridade em arquétipos negativos definidos pelo blackface. Miguel Covarrubias, por exemplo, era mexicano e próximo da intelectualidade do Harlem; Belmonte, paulistano, era afrodescendente (Gorberg, 2018). Suas origens e seus círculos de sociabilidade não os impediram de perpetuar visões preconceituosas, aceitas e reproduzidas na sociedade de seu tempo.

Contudo, em sentido inverso, em que pese o preconceito evidente naquelas criações, há que se ressaltar a ambivalência que perpassava sua elaboração; a elite branca que consumia aquelas revistas parecia cada vez mais interessada e fascinada pela cultura negra, amplamente disseminada nas caricaturas de notórios veículos de mídia impressa.

O sucesso dos artistas negros estava conectado à negrofilia europeia e aos debates intelectuais sobre o papel da presença africana nas identidades nacionais e culturais, mas não pode ser atribuído apenas a esses vetores; as caricaturas também fazem pensar na ação de sujeitos sociais que encontraram novos canais de visibilidade, atuação e afirmação, enquanto conferiam novos sentidos a seu legado musical.

\section{REFERÊNCIAS}

ABREU, Marcia; DEAECTO, Marisa Midori (Orgs.). A circulação transatlântica dos impressos: conexões. Campinas: UNICAMP; IEL; Setor de Publicações, 2014.

ABREU, Martha. Da senzala ao palco: canção escrava e racismo nas Américas, 18701930 [eBook]. Campinas: Editora da Unicamp, 2017.

ALMEIDA, Silvia Capanema; SILVA, Rogério Sousa. Do (in)visível ao risível: o negro e a "raça nacional" na criação caricatural da Primeira República. Estudos Históricos, Rio de Janeiro, v. 26, n. 52, pp. 316-345, dez. 2013. 
ANDREWS, George Reid. Visões Afro-americanas sobre o Brasil, 1900-2000. Revista de Ciências Sociais, Fortaleza, v. 48, n. 2, pp. 20-52, 2017.

ARCHER-STRAW, Petrine. Negrophilia: Avant-Garde Paris and Black Culture in the 1920s. London: Thames and Hudson, 2000.

BARROS, Orlando de. Corações de Chocolat: A história da Companhia Negra de Revistas (1926-1927). Rio de Janeiro: Livre Expressão, 2005.

BASTOS, Rafael José de Menezes. Les Batutas, 1922: uma antropologia da noite parisiense. Revista brasileira de Ciências Sociais, São Paulo, v. 20, n. 58, pp. 177-196, 2005.

BHABHA, Homi K. Remembering Fanon: Self, Psyche, and the Colonial Condition. Introduction to Frantz Fanon. In: FANON, Fritz. Black Skin, White Masks. London and Sydney: Pluto Press, 1986. pp. vii-xxvi.

BHABHA, Homi K. A questão do outro: diferença, discriminação e o discurso do colonialismo. In: HOLLANDA, Heloísa Buarque de (Org.). Pós-modernismo e política, Rio de Janeiro: Rocco, 1992. pp. 177-205.

CABRAL, Sérgio. Pixinguinha: vida e obra. Rio de Janeiro, Funarte, 1978.

CABRAL, Sérgio. No tempo de Ari Barroso. Rio de Janeiro: Lumiar, 1993.

CARDOSO, Rafael. O moderno e o arcaico em J. Carlos. In: LOREDANO, Cassio; KOVENSKY, Julia; PIRES, Paulo Roberto (Orgs.). J. Carlos: Originais. São Paulo: IMS, 2019. pp. 178-187.

CARETA, Rio de Janeiro, n. 964, p. 23, 11 dez. 1926.

CORREIO DA MANHÃ, Rio de Janeiro, n. 9009, 08 nov. 1923.

COSTALLAT, Benjamim. Fitas. Rio de Janeiro: Costallat \& Miccolis, 1924.

COSTALLAT, Benjamim. Paysagem sentimental. Rio de Janeiro: Ed. José Olympio, 1936.

DOMINGUES, Petrônio. Tudo preto: a invenção do teatro negro no Brasil. Luso-Brazilian Review, v. 46, n. 2, pp. 113-128, 2009.

DUMENIL, Lynn. The Modern Temper: American Culture and Society in the 1920s. New York: Hill and Wang, 1995.

FANON, Frantz. Black Skin, White Masks. London and Sidney: Pluto Press, 1986.

FRANÇA, Patrícia de Souza. "Livros para leitores": a atuação literária e editorial de Benjamim Costallat no Rio de Janeiro dos anos 1920. Rio de Janeiro: Fundação Biblioteca Nacional, 2011.

FROU-FROU, Rio de Janeiro, n. 3, ago., 1923.

FROU-FROU, Rio de Janeiro, n. 22, dez., 1924.

FROU-FROU, Rio de Janeiro, n. 36, mai., 1926.

GAZETA DE NOTÍCIAS, Rio de Janeiro, n. 19, 22 jan. 1922.

GILROY, Paul. O Atlântico negro: modernidade e dupla consciência. São Paulo; Rio de Janeiro: Editora 34; UCM, 2001. 
GOMES, Tiago de Melo. Negros contando (e fazendo) sua história: alguns significados da trajetória da Companhia Negra de Revistas (1926). Estudos afro-asiáticos, v. 23, n. 1, pp. 53-83, 2001.

GORBERG, Marissa. Um olhar sobre as caricaturas de Belmonte (1923-1927). Tese (Doutorado em História, Política e Bens Culturais) - Centro de Pesquisa e Documentação, Fundação Getúlio Vargas. Rio de Janeiro, 2018.

HEAP, Chad. Slumming: Sexual and Racial Encounters in American Nightlife, 18851940. Chicago and London: The University of Chicago Press, 2009.

HERTZMAN, Mark A. Making Samba: A New History of Race and Music in Brazil. Durham; London: Duke University Press, 2013.

HOBSBAWM, Eric J. História Social do Jazz. São Paulo: Paz e Terra, 2009.

ILUSTRAÇÃO BRASILEIRA, Rio de Janeiro, n. 66, fev., 1926.

KALICH, Natalie. Sketching Out America's Jazz Age in British Vogue. In: CLAY, Catherine et al. (Orgs.). Women's Periodicals and Print Culture in Britain, 1918-1939: The Interwar Period. Edinburgh: Edinburgh University Press, 2018. pp. 42-57.

KLADDERADATSCH, Berlin, n. 18, mai., 1923a.

KLADDERADATSCH, Berlin, n. 32, p. 9, ago., 1923b.

LABRES FILHO, Jair Paulo. Que jazzé esse?: As jazz-bands no Rio de Janeiro da década de 1920. Dissertação (Mestrado em História) - Universidade Federal Fluminense. Niterói, 2014.

LIFE, New York, 15 jul., 1926.

LEE, Yhe-Young. Controversies about American Women's Fashion, 1920-1945: through the lens of The New York Times. Dissertation (Doctor of Philosophy) - Iowa State University. Ames, Iowa, 2003.

LOCKE, Alain LeRoy. The New Negro: An Interpretation. New York: Arno Press; The New York Times, 1968 [1925].

LOTT, Eric. Love and Theft: Blackface Minstrelsy and the American Working Class (Race and American Culture). Oxford: Oxford University Press, 1993.

A MAÇÃ, Rio de Janeiro, n. 2, p. 9, 18 fev. 1922.

O MALHO, Rio de Janeiro, n. 1042, 02 set. 1922.

O MALHO, Rio de Janeiro, n. 1.108, dez., 1923.

O MALHO, Rio de Janeiro, n. 1152, out. 1924.

O PAIZ, Rio de Janeiro, n. 14168, 05 ago. 1923.

PARA TODOS, Rio de Janeiro, n. 391, jun., 1926.

PARA TODOS, Rio de Janeiro, n. 439, mai., 1927a.

PARA TODOS, Rio de Janeiro, n. 441, mai., 1927b.

PERREAULT, Isabelle. De l'américanisme en France: le statut paradoxal de la musique jazz (1920-1930). Babel, n. 28, pp. 167-184, 2013.

PIETERSE, Jan Nederveen. White on Black: Images of Africa and Blacks in Western Popular Culture. New Haven; Conn.; London: Yale University Press, 1992. 
PUTNAM, Lara. Radical Moves: Caribbean Migrants and the Politics of Race in the Jazz Age. Chapel Hill: The University of North Carolina Press, 2013.

D. QUIXOTE, Rio de Janeiro, n. 348, p. 13, 1924.

ROSENTHAL, Angela. No Laughing Matter: Visual Humour in Ideas of Race, Nationality, and Ethnicity. Hanover, New Hampshire: Dartmouth College Press, 2016.

THOMPSON, Ayanna. Blackface. New York; London; Oxford: Bloomsbury Academic, 2021.

SCHUSTER, Sven. História, nação e raça no contexto da Exposição do Centenário em 1922. História, Ciências, Saúde-Manguinhos [online]. Rio de Janeiro, v. 21, n. 1, pp. 121-134, 2014.

SEIGEL, Micol. Uneven Encounters: Making Race and Nation in Brazil and the United States. Durham; NC; London: Duke University Press, 2009.

SHAW, Lisa. Tropical Travels: Brazilian Popular Performance, Transnational Encounters, and the Construction of Race. Austin: University of Texas Press, 2018.

SOUZA, Vanderlei Sebastião de. A eugenia brasileira e suas conexões internacionais: uma análise a partir das controvérsias entre Renato Kehl e Edgard Roquette-Pinto, 1920-1930. História, Ciências, Saúde-Manguinhos [online]. Rio de Janeiro, v. 23, supl. 1, pp. 93-110, 2016.

STOVALL, Tyler Edward. Paris Noir: African-Americans in the City of Light. Boston, MA: Houghton Mifflin, 1996.

SWEENEY, Fionnghuala; MARSH, Kate (Orgs.). Afromodernisms: Paris, Harlem and the Avant-Garde. Edinburgh: Edinburgh University Press, 2013.

TEIXEIRA, Luiz Guilherme Sodré. O traço como texto: a história da charge no Rio de Janeiro de 1860 a 1930. Rio de Janeiro: Fundação Casa de Rui Barbosa, 2001.

TRAVASSOS, Elizabeth; LAGO, Manoel Aranha Corrêa do. Darius Milhaud e os "compositores de tangos, maxixes, sambas e cateretês". Revista Brasileira, Fase VII, n. 43, ano 11, pp. 109-143, 2005.

VANITY FAIR, New York, jul., p. 65, 1926.

VIANNA, Hermano. O mistério do samba. Rio de Janeiro: Jorge Zahar Editora; Editora UFRJ, 1995.

LA VIE PARISIENNE, n. 32, ago, 1921.

LA VIE PARISIENNE, n. 5, jan., 1925.

LA VIE PARISIENNE, n. 2, dez., 1927.

VOGUE, London, late february, pp. 52-53, 1925.

WIPPLINGER, Jonathan O. The Jazz Republic: Music, Race, and American Culture in Weimar Germany. Ann Arbor: The University of Michigan Press, 2017. 


\section{NOTAS}

${ }^{1}$ A expressão "The New Negro" foi popularizada pelo autor Alain Locke em sua obra homônima publicada em 1925 (Locke, 1968 [1925]), usada para denominar o movimento cultural que se desenvolvia no Harlem novaiorquino.

2 Tradução livre para "Les derniers représentants de la vieille gaîté française”. A expressão, difundida na França, remetia ao "velho espírito francês" do Antigo Regime e intitulou uma canção do séc. XIX.

${ }^{3}$ Isaac Frankel foi homenageado num editorial sobre sua trajetória, publicado n’A Maçã, n. 51, em 27 de fevereiro de 1923.

${ }^{4}$ Até então, a maioria das mulheres usava meias-calças até a cintura. Mostrar os joelhos indicava uma ousada tendência (Lee, 2003, p. 37).

${ }^{5}$ No original: "Nègrerie is to the Twentieth Century what Chinoiserie was to the Eighteenth".

${ }^{6}$ A revista Kladderadatsch era vendida no Rio de Janeiro desde fins do século XIX, assim como a francesa La Vie Parisienne e outras. Nos anos 1920, algumas de suas caricaturas eram pontualmente republicadas em periódicos nacionais como Revista da Semana e D. Quixote. 